\title{
CALCULATION OF SEISMICALLY LOADED EARTH RETAINING STRUCTURES
}

\author{
JAn PrušKa*, Veronika PaVelcová \\ Czech Technical University in Prague, Faculty of Civil Engineering, Thákurova 7, 16629 Prague, Czech \\ Republic \\ * corresponding author: jan.pruska@cvut.cz
}

\begin{abstract}
Eurocode 1998-5 for the design of earth retaining structures in seismic conditions describes calculations using the Mononobe-Okabe method. This simplified quasi-static procedure is to some extent very conservative. The article describes the limits of this method and brings out the comparison using theoretical numerical examples with other approaches. The first, is a calculation method introduced in the American NHCRP 661, the second, is the Chen and Liu method and the last one is the Mylokanis et al. method.
\end{abstract}

KEYWORDS: Earth retaining structures, seismicity, seismic coefficient, earth pressure, Mononobe-Okabe.

\section{INTRODUCTION}

The theory of Coulomb and Rankin has formed the basis for current commonly used theories of earth pressure calculation. During the 20th century, it was found that earth pressures during seismic action can be significantly higher than in the case of purely static loading conditions. Okabe (1924) and Mononobe \& Matsuo (1929) introduced the first method that could calculate the total earth pressure from static and seismic loading. This method became known as the Mononobe - Okabe method (hereinafter M-O) and is recommended in many geotechnical standards. The Eurocode 1998-5 for the design of retaining and gravity walls in seismic conditions also provides a calculation using this method.

The M-O method as a simplified quasi-static procedure that is to some extent very conservative. The article describes the limits of this method, and finds comparison with other approaches for the calculation of seismically loaded retaining walls in the American NHCRP 661, also in the method of Chen and Liu (1990) and in an alternative to the standard M-O method given by Mylonakis et al.

\section{SEISMIC LOADING}

For quasi-static calculations of gravity and retaining walls, the seismic soil load is given by horizontal and vertical forces which are equal to the weight of the active wedge $W$ and the corresponding seismic coefficient $k_{h}, k_{v}$, see Figure 1. The vertical load must be considered to have the most adverse effect. The value of the seismic coefficient is generally determined to be equal to the ratio of the considered acceleration and gravitational acceleration and it is possible to determine the relationships according to the different authors.

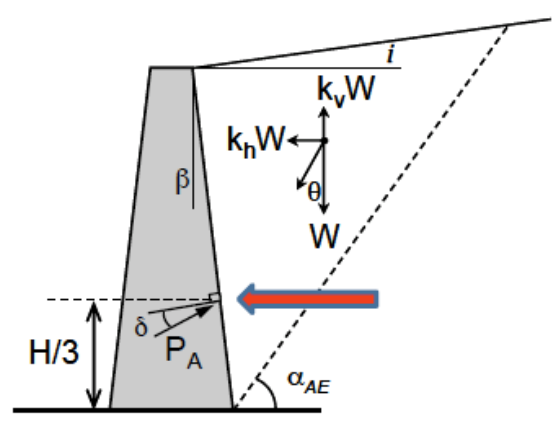

FIGURE 1. Wall load during quasi-static calculation

2.1. According to Terzaghi (1950)

$$
\begin{aligned}
& k_{h}=\frac{a_{h}}{g} \\
& k_{v}=\frac{a_{v}}{g}
\end{aligned}
$$

where:

$a_{h}$ design acceleration in the horizontal direction $\left[m \cdot s^{-2}\right]$

$a_{v}$ design acceleration in the vertical direction $\left[\mathrm{m} \cdot \mathrm{s}^{-2}\right]$

$g$ gravitational acceleration $\left[m \cdot s^{-2}\right]$

\subsection{According to Gutenberg And} RiCHTER (1956)

$$
\begin{gathered}
k_{h}=\frac{a_{0}}{g} \\
\log _{10} a_{0}=-2.1+0.81 M_{s}-0.027 M_{s}^{2}
\end{gathered}
$$

where:

$a_{0}$ earthquake acceleration with magnitude $M_{s}$ $\left[m \cdot s^{-2}\right]$ 
2.3. AcCording to Eurocode 1998-5

$$
k_{h}=\frac{S}{r}
$$

$$
\begin{array}{ll}
k_{h}= \pm 0.50 k_{h} & \text { if both } a_{v} \text { and } g>0.6 \\
k_{h}= \pm 0.33 k_{h} & \text { for other cases }
\end{array}
$$

where:

$S$ the subsoil coefficient defined in Eurocode 1998-1 $[-]$

$r$ coefficient according to Table 1$][-]$

For walls lower than $10 \mathrm{~m}$, the seismic coefficient must be constant in height. Eurocode 1998-5 does not specify a procedure for determining the effect of higher walls on the value of seismic loading.

\subsection{ACCORDING TO NCHRP 611 AND AASHTO}

The National Cooperative Highway Research Program (NCHRP) is a research program of the United States of America. Road infrastructure research is funded by the American Association of State Highway and Transportation Officials (AASHTO). Report 611 presents current results from the research of seismic design of road infrastructure, including slopes and load-bearing structures. Determination of seismic acceleration is not found in the NCHRP 611 report itself but in superior document: LRFG Bridge Design Specifications (AASHTO, 2007 and 2012). Report 611 NCHRP concerns this report in Chapters 5 and 7 . It introduces the factor $\alpha$ which takes into account the height of backfill.

$$
k_{h, N C H R P}=\frac{F_{P G A} P G A \alpha}{g}
$$

where:

$k_{h, N C H R P}$ horizontal seismic coefficient $k_{h, d}$ as defined in $\operatorname{AASHTO}(2007 / 2012)[-]$

$F_{P G A}$ locality coefficient for the zero period in the elastic response spectrum - values in Table 3.10.3.2-1 AASHTO (2012) [-]

$P G A$ peak soil level acceleration for bedrock (class B) $\left[\mathrm{m} \cdot \mathrm{s}^{-2}\right]$

$\alpha$ backfill height coefficient [-] $g$ gravitational acceleration $\left[m \cdot s^{-2}\right]$

The backfill height coefficient $\alpha$ described in the 611 NCHRP report is the result of a one-dimensional free field wave propagation analysis. The analysis took into account the fact that the acceleration of the backfill of the supporting structure is not the same at any point. This coefficient can be calculated for soils of classes C, D and E (equivalent to all soils except rock and very soft clay) according to AASHTO as follows:

$$
\alpha=1+0.003 H\left[\left(0.5 \frac{F_{v} S_{1}}{F_{P G A} P G A}\right)-1\right]
$$

$H$ height of load-bearing structure or backfill $[m]$

$F_{v}$ locality coefficient for long-term range in the elastic response spectrum according to Table 3.10.3.2-3 AASHTO (2012) [-]

$S_{1}$ horizontal spectral acceleration coefficient for a period of $1 \mathrm{~s}$ in rock (class B) $\left[m \cdot s^{-2}\right]$

However, Equation (9) can only be used if the height of the supporting structure is $H>6 \mathrm{~m}$. For the construction of a height $H \geq 30 \mathrm{~m}$, the height in Equation (9) must be set to $H=30 \mathrm{~m}$. The backfill height coefficient corresponds to the function correction coefficient $q_{h}$ according to Swiss SIA 267.

\section{Mononobe-Okabe Method}

Following the 1923 earthquake in Kanto, Japan, Okabe (1924) and Mononobe \& Matsuo (1929) performed a series of experiments on a vibrating table. A pseudostatic method (introducing the principle of equivalent accelerations) based on the obtained experimental results was derived to calculate the total earth pressure from both static and seismic loading. This method (known as the Mononobe-Okabe method), based on the Coulomb's limit approach and the assumption that the earth pressure is derived from a rigid body that moves along a shear plane, and gives relations for active or passive earth pressure under seismic loading as follows (the sign convention is in Figure 2):

$$
\begin{aligned}
P_{a e} & =\frac{1}{2} \gamma\left(1 \pm k_{v}\right) H^{2} K_{a e} \\
P_{p e} & =\frac{1}{2} \gamma\left(1 \pm k_{v}\right) H^{2} K_{p e}
\end{aligned}
$$




\begin{tabular}{lc}
\hline Type of gravity or retaining wall & $\mathrm{r}$ \\
\hline Free gravitational walls that can deviate up to $d_{r}=300 \alpha \cdot S[\mathrm{~mm}]$ & 2.0 \\
\hline Free gravitational walls that can deviate up to $d_{r}=200 \alpha \cdot S[\mathrm{~mm}]$ & 1.5 \\
\hline $\begin{array}{l}\text { Flexible concrete walls, anchored or spread walls, reinforced concrete walls } \\
\text { founded on vertical piles, embedded foundation walls and bridge abutments }\end{array}$ & 1.0 \\
\hline
\end{tabular}

TABLE 1. Values of the coefficient $r$ for the calculation of the horizontal seismic coefficient $(\alpha$ is the ratio of the design acceleration $a_{d}$ for the foundation soil type A to the gravitational acceleration $g, S$ is the subsoil coefficient defined in Eurocode 1998-1)

The following notation is used as in the previous equations:

$\gamma$ volumetric density of soil $\left[k N \cdot m^{-3}\right]$

$H$ height of load-bearing structure $[\mathrm{m}]$

$K_{a e}$ active earth pressure coefficient (static + dynamic) $[-]$

$K_{p e}$ passive earth pressure coefficient $($ static + dynamic) $[-]$

$\alpha$ inclination of the back of the wall $\left[^{\circ}\right]$

$\beta$ backfill inclination behind the retaining wall $\left[^{\circ}\right]$

$\delta$ angle of friction between the soil and the wall structure $\left[^{\circ}\right]$

$\varphi$ angle of internal friction of the backfill material [ ${ }^{\circ}$ ]

$k_{h}$ seismic coefficient of horizontal acceleration [-]

$k_{v}$ seismic coefficient of vertical acceleration [-]

$\theta \tan ^{-1}\left(\frac{k_{h}}{1-k_{v}}\right)[-]$
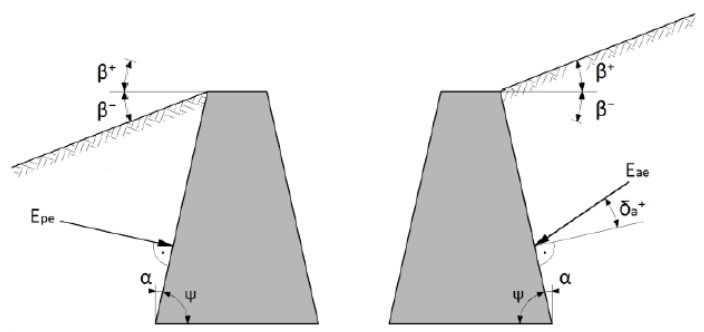

FIGURE 2. Sign convention (left: passive, right: active)

In many cases, the seismic coefficient of vertical acceleration $k_{v}$ in these examples is neglected because the effect of vertical acceleration is relatively small.

\subsection{Limits of the Mononobe-OKabe METHOD}

The relations of the M-O method are based on the following assumptions of the Mohr-Coulomb theory of soil failure with a criterion according to the Coulomb theory:

- dry, homogeneous, isotropic backfill material

- the soil above the shear plane is solid - it creates a wedge
- the soil under the supporting structure is loadbearing

- seismic load is modelled as a static force (multiple of $k_{h, d}$ )

- the wall must be able to move or rotate so that a shear plane can form in the soil

- the resulting shear plane is planar

- the terrain above the wall is modelled as an infinitely long slope

The last two items in this list are responsible for problems using the M-O method

If the slope (backfill) behind the wall $\beta$ reaches or exceeds the inclination of the shear plane, the result is an infinitely large "wedge" of soil. As a result, the calculated active earth pressure is infinitely large and the relations of the $\mathrm{M}-\mathrm{O}$ method no longer provide a solution for these inclinations. Proof of the limited validity of Equation (12) can simply be shown by the example of determining the stability of an infinitely long slope with a planar shear plane where the slope is formed by incoherent soil and there is no water in it. The seismic load is given by the horizontal acceleration $k_{h, d}=a_{h, d} / g$ and the vertical acceleration $k_{v, d}$ is neglected. It is known that such a slope is stable if the inclination $\beta$ is less than the angle $(\varphi-\theta)$ or in the extreme case $\beta=\varphi-\theta$ when the shear plane is exactly parallel to the inclination of the surface. When using Equation 12 for the active earth pressure coefficient, for $k_{h, d}=0.1 ; \beta=30^{\circ}, \varphi=35^{\circ}$, the expression $\sin (\varphi-\beta-\theta)$ below the square root becomes negative and no natural solution can be found.

Another limitation is, that the M-O method has only limited suitability for calculating passive earth pressure from seismic loading because in many cases the shear plane at passive earth pressure does not have to be considered horizontal but logarithmic. If we compare the value of passive earth pressure using the logarithmic shape of the shear plane and the horizontal one (which the M-O method considers), it can be seen that a planar plane can cause significant overestimation of the resistance to passive earth pressure, especially when considering the angle between the soil and the wall structure $\delta=2 / 3 \varphi$. The last disadvantage of the M-O method is the assumption of a constant seismic load over the entire height of the structure (i.e. the soil wedge). 


\section{Eurocode 1998-5}

Appendix E gives two formulas for calculating the active earth pressure coefficient $K_{a e}$. For the inclination of the terrain surface behind the wall $\beta \leq \varphi-\theta$ uses the Equation $(12$ according to M-O. But if the angle of the inclination behind the wall satisfies the condition $\beta>\varphi-\theta$, the original relationship is modified by complete exclusion of the influence of the inclination of the terrain surface behind the wall $\beta$ as follows:

$$
K_{a e}=\frac{\cos ^{2}(\varphi-\theta-\alpha)}{\cos \theta \cos ^{2} \alpha \cos (\delta+\theta+\alpha)}
$$

Thus, for the inclinations of the terrain behind the wall with values of the angle $\beta>\varphi-\theta$, a limit arises where the original relation (Equation $(12)$ ) calculates the infinite coefficient of earth pressure $K_{a e}$ but Equation (14) gives a constant value of the coefficient $K_{a e}$. The inclination of the terrain behind the retaining wall can therefore be arbitrarily increased above the value $\varphi-\theta$ according to the Equation (14) without increasing the soil pressure (see Figure 3). In this way, the fact that the slope above the wall is already unstable and theoretically the whole area must be supported by the supporting structure so that its displacement does not occur can be missed. Therefore, the use of the Equation (14) is unsuitable in the case of very steep slopes of the terrain above the wall.

The calculations for this paper have been carried out in the GEO5 program which has, inter alia, a procedure according to Eurocode 1998-5 built-in. The advantage of this program is that at the values of the inclination $\beta>\varphi-\theta$ it notifies the user to this fact and possible problems related to it.

Eurocode 1998-5 uses the Equation 13 to calculate the passive earth pressure coefficient $K_{p e}$. However, it is recommended to use this equation mainly for the vertical front side of the wall. In addition, it requires consideration of the friction between the wall and the soil $\delta_{p}=0^{\circ}$ (Section 7.3.2.3 (6)) which leads to very conservative results.

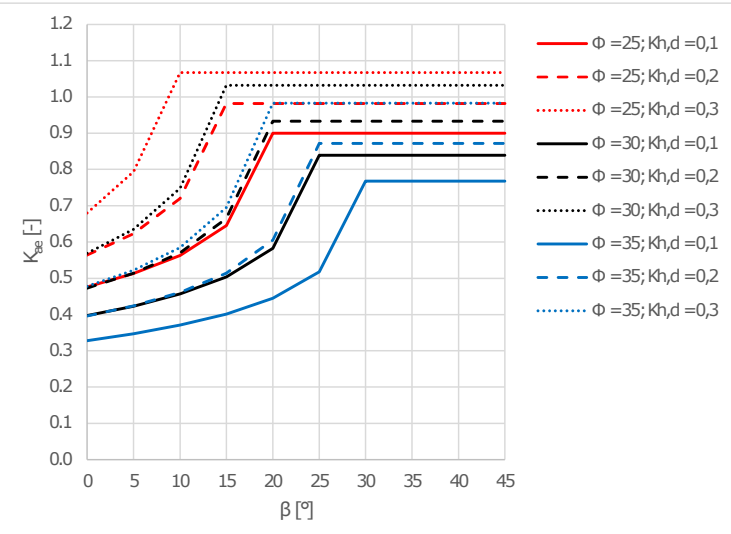

FiguRE 3. Dependence of the inclination of the terrain behind the wall and the coefficient $K_{a e}$ according to Eurocode 1998-5

\section{Chen And LiU}

Chen and Liu's method is based on Chang's doctoral dissertation (1981). As with the M-O method, it is based on a kinematic approach. However, it considers a logarithmic shear plane instead of a horizontal shear plane for the M-O method. Chen and Liu (1990) also present tabular values of earth pressure coefficients for the most common cases of retaning walls and backfill soils. This method generally provides lower passive earth pressures than the M-O method (for the same value of friction between wall and soil).

\section{NCHRP 611}

The Shamsabadi method (2007), recommended by NCHRP 611, is a kinematic method that considers the logarithmic shear plane and the hyperbolic relationship between stress and strain. Thus, this method differs from conventional kinematic methods such as Chen and Liu (1990). Standard NCHRP 611 (2008) in Appendix 5 gives graphs for the passive earth pressure coefficient $K_{p e}$ as a function of variables: soil cohesion $c$, wall height $H$, soil volumetric density $\gamma$, seismic coefficient $k_{h}$ and soil internal friction angle $\varphi$.

\section{MYLONAKIS ET AL.}

In 2007, Mylonakis et al. presented a closedform stress plasticity solution for gravitational and earthquake-induced earth pressures on retaining walls. The proposed solution is essentially an approximate yield-line approach, based on the theory of discontinuous stress fields. It is an alternative to the standard $\mathrm{M}-\mathrm{O}$ equations for seismic earth pressures suffering thus from the same limits as the M-O method. On the other hand this alternative approach works with respect to active and passive conditions, as it can be expressed by a single equation with opposite signs for soil friction angle and wall roughness. According to this method the active and passive presure under seismic loading can be determined by:

$$
P_{e}=\frac{1}{2} \gamma\left(1-k_{v}\right) H^{2} K_{e}
$$

where

$$
\begin{aligned}
K_{e}= & \frac{\cos (\alpha-\beta) \cos (\beta+\theta)}{\cos \theta \cos \delta \cos ^{2} \alpha} . \\
& \cdot\left[\frac{1 \mp \sin \varphi \cos \left(\Delta_{2} \mp \delta\right)}{1 \pm \sin \varphi \cos \left[\left(\Delta_{1} \pm(\beta+\theta)\right]\right.}\right]^{\left(\mp 2 \psi_{e} \tan \varphi\right)}
\end{aligned}
$$

The Caquot angles $\Delta_{1}, \Delta_{2}$ are given by mathematical expressions

$$
\begin{aligned}
& \sin \Delta_{1}=\frac{\sin \beta}{\sin \varphi} \\
& \sin \Delta_{2}=\frac{\sin \delta}{\sin \varphi}
\end{aligned}
$$


and twice the revolution angle of principal stresses in the two regions under seismic conditions

$$
2 \psi_{e}=\Delta_{2} \mp\left(\Delta_{1}+\delta\right)+\beta-2 \alpha-\theta
$$

The upper signs in the equations refers to active conditions $P_{a e}$ and the lower signs to passive $P_{p e}$ and the notation used in equations above is the same as in the standard M-O method (Section 3).

\section{Comparison of Methods with the Active Seismic Earth Pressure Coefficient}

To compare the methods of Chen and Liu, Mylonakis at el. and M-O with the modification given by the Equation (14) for backfill inclinations $\beta>\varphi-\theta$ according to the Eurocode 1998-5, a simple case was deliberately chosen: a gravity wall with a vertical back side of the wall $\left(\alpha=0^{\circ}\right)$ with a height $H=3 \mathrm{~m}$ and a wall friction angle $\delta=2 / 3 \varphi$, inclination of the terrain surface $\beta=0-30^{\circ}$, soil friction angle $\varphi=30^{\circ}$, cohesion $c=30 \mathrm{kPa}$. The vertical acceleration of the earthquake was neglected, the horizontal acceleration $k_{h, d}$ is 0.1 and 0.2 , respectively (see Figure 4.
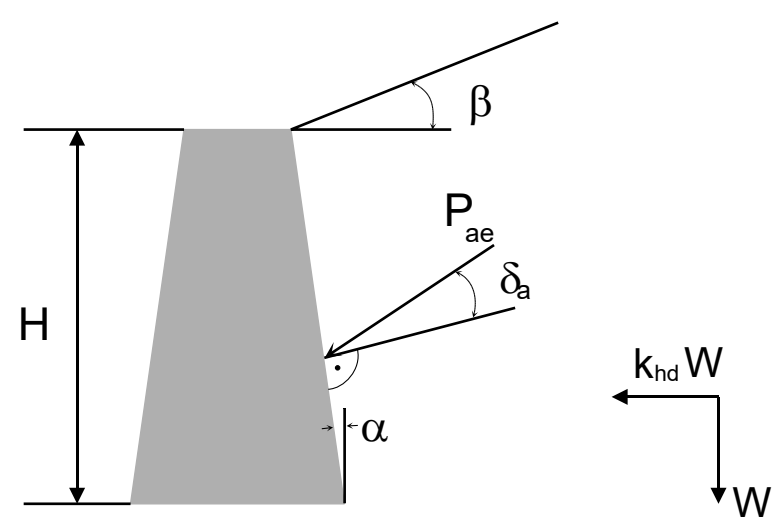

FIGURE 4. Scheme of solved example

The differences between methods are minor for higher inclinations of the terrain surface $\beta$ (Figures 5). The reason for this is the fact that the logarithmic shear plane considered by Chen and Liu's method becomes practically flat for the calculations of the active earth pressure coefficient performed here. As mentioned before, it can be observed that Mylonakis's et al. method is not able to give any natural solution after exceeding the critical backfill inclination $\beta$. The peculiarity of the Chen and Liu's (1990) method is evident from both graphs in Figure 5 where it can be seen that the method gives results even for backfill inclinations above the critical inclination $\beta$ although for very steep slopes these values are already above the physically permissible limit (and the slope would be unstable). Signs of Chen and Liu's logarithmic shear plane are visible only in Figure 5 (bottom) as the values of the active earth pressure coefficient slightly differs from other methods.

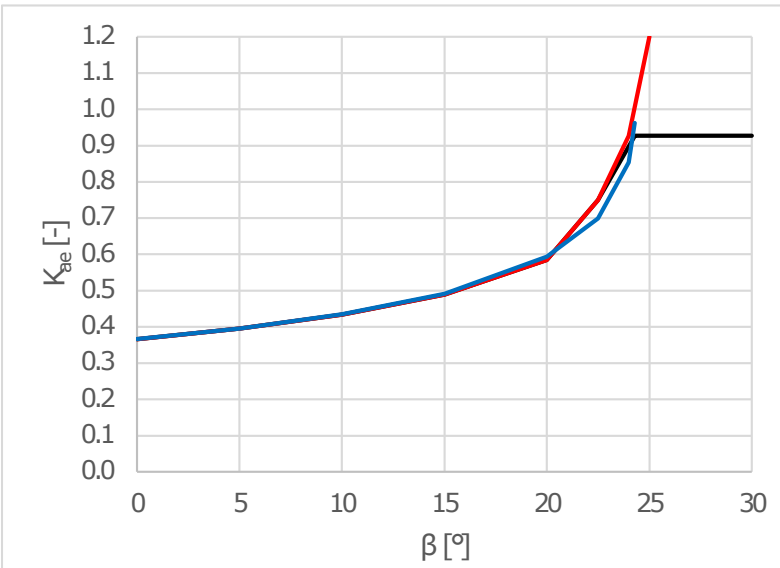

—Mononobe-Okabe _Chen \& Liu _ Mylonakis et al.

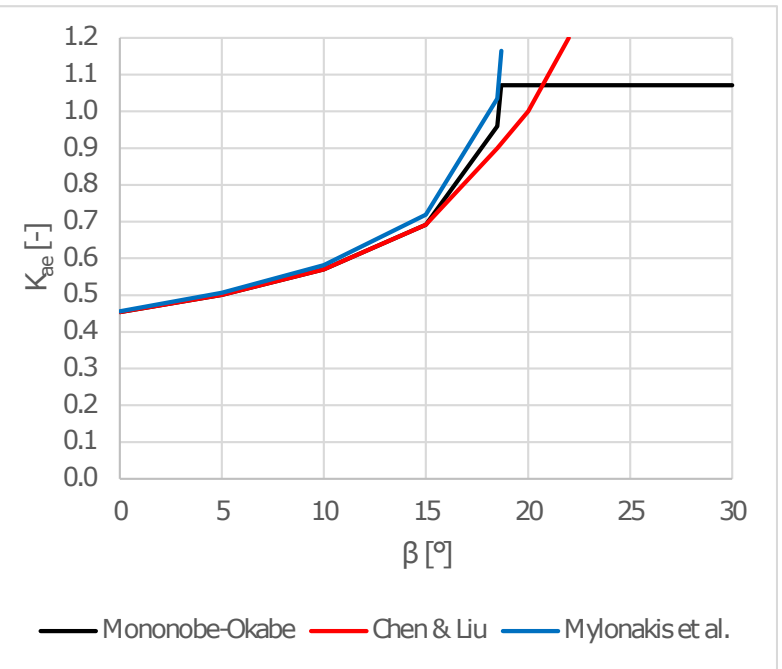

FiguRE 5. Comparative calculations of the effect of cohesion on active seismic earth pressure coefficient: $k_{h}=0.1$ (top) and $k_{h}=0.2$ (bottom).

\section{Comparison of Methods with the Passive Seismic Earth Pressure Coefficient}

To compare the values of the passive earth pressure coefficient $K_{p e}$ according to Chen and Liu (1990) and Eurocode 1998-5 (Figure 6) a gravity wall with a vertical back side of the wall $\left(\alpha=0^{\circ}\right)$, with a height $H=3 \mathrm{~m}$ and horizontal backfill surface behind the wall $\beta=0^{\circ}$ was chosen. Not only the standard M-O method, as the Eurocode 1998-5 recommends, but also the alternative approach of the M-O method presented by Mylonakis et al., (as it should theoretically give exactly the same results as the standard M-O method), was used for the calculation. For the Chen and Liu (1990) method, the wall friction angle equals $\delta=$ $2 / 3 \varphi$, for Eurocode 1998-5 (M-O and Mylonakis et al.) $\delta=0^{\circ}$ (prescribed by the standard), the internal friction angle $\varphi$ was considered from $25^{\circ}$ to $35^{\circ}$. The vertical acceleration of the earthquake was neglected, the horizontal acceleration of $k_{h, d}$ took values of 0 , $0.1,0.2$ and 0.3 . 


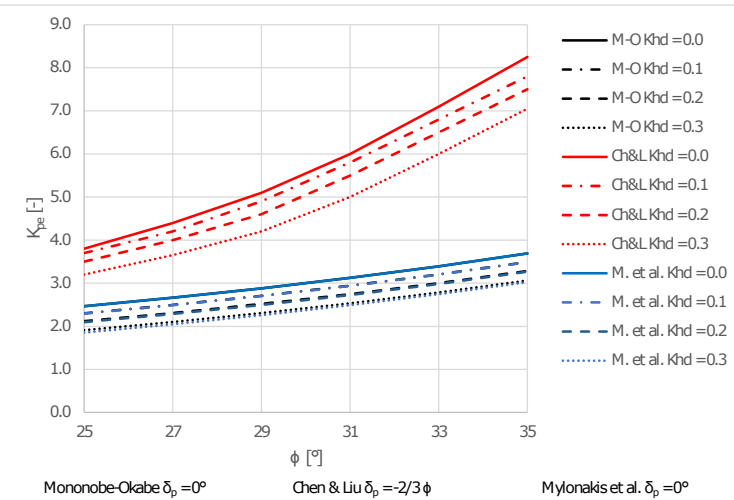

Figure 6. Comparison of methods for calculating the passive coefficient of seismic earth pressure

According to the literature, the procedures recommended by Eurocode 1998-5 give $\left(\delta=0^{\circ}\right)$ (which corresponds to its requirements) the most conservative values of all the methods. In fact the Method of Mylonakis et al. gives even lower values of passive pressure coefficient than the standard M-O method but taking into account the scale of the values of Chen and Liu's method, the difference is insignificant. If the value $\delta=-2 / 3 \varphi$ was used for the friction between the wall and the soil using the standard M-O method, higher coefficients of passive earth pressure would be obtained than by following the Chen and Liu's method (1990). However, since many derivations of the passive seismic pressure coefficient $K_{p e}$ reported in the literature are controversial, it is recommended to use the calculation involved in the M-O method according to Eurocode $8\left(\delta_{p}=0^{\circ}\right)$.

\section{Conclusion}

It should be noted that the M-O method represents a considerable simplification of reality. In addition to the limitations of all pseudo-static methods, it should be emphasized that the frequency range of excitation or soil stiffness are not taken into account in seismic loading while using the M-O method. In the case of solving the problem with the value of the inclination of the terrain $\beta$, we obtain constant values of the coefficient of active earth pressure $K_{a e}$ for and above critical inclination angle $\beta$ using Eurocode 19985 and while determinating the passive earth pressure according to Eurocode 1998-5, the requirement of friction between the wall and the soil $\left(\delta_{p}=0^{\circ}\right.$ ) (Section 7.3.2.3) has to be satisfied. In both of the mentioned cases, it seems more advantageous to use the Chen and Liu's method. Another disadvantage is that when calculating walls higher than $10 \mathrm{~m}$, Eurocode 1998-5 does not specify the procedure for determining the seismic load (unlike the American NCHRP 611).

It also cannot be overlooked that the classical M-O equations are empirical and hardly derived by physicbased reasoning. On the other hand, the alternative approach presented by Mylonakis et al. proposes a simpler solution in which the main features of the mathematical expressions, including signs, can be deduced by such reasoning from physics. Moreover, the proposed solution is symmetric with respect to active and passive conditions, as it can be expressed by a single equation with opposite signs for soil internal friction angle $\varphi$ and angle of friction between the soil and the wall structure $\delta$.

Despite all the limitations and possible shortcomings, the M-O method is still used as an easy-tounderstand and meaningful method for the calculation of seismic loaded earth retaining structures. Also Eurocode 1998-5: Eurocode 8: Design of structures for earthquake resistance - Part 5: Foundations, retaining structures and geotechnical aspects explicitly refers to this method in Appendix E.

\section{ACKNOWLEDGEMENTS}

The support provided by the SGS project No. SGS21/045/OHK1/1T/11.

\section{REFERENCES}

[1] AASHTO. LRFD Bridge Design Specifications, vol. 4th edition. American Association of State Highway and Transportation Officials, 2007.

[2] Eurocode 8. : Design of structures for earthquake resistance-part 5: Foundations, retaining structures and geotechnical aspects en 1998-5: 2004. Brussels: European Committee for Standardization 2006.

[3] FHWA (Federal Highway Administration). Seismic retrofitting manual for highway structures. Part 1, Bridges. Tech. rep., Turner-Fairbank Highway Research Center, 2006.

[4] GEO 5. User manual. http://www.fine.cz

[5] B. Gutenberg, C. Richter. Magnitude and energy of earthquakes. Annali di Geofisica 9:1-15, 1956.

[6] W.-F. Chen, X. Liu. Limit analysis in soil mechanics. Elsevier, 1990.

[7] N. Mononobe. On determination of earth pressure during earthquake. In Proc. World Engineering Congress, vol. 9, pp. 177-185. 1929.

[8] NCHRP 611. Seismic analysis and design of retaining walls, buried structures, slopes, and embankments. 2008.

[9] S. Okabe. General theory of earth pressure. Journal of theJapanese Society of Civil Engineers-1926-12 (1) 311, 1926.

[10] Pruška. Dynamika geotechnických konstrukcí. ČVUT FSv, 2017.

[11] A. Shamsabadi. Three-dimensional nonlinear seismic soil-abutment-foundation-structure interaction analysis of skewed bridges. University of Southern California, 2007.

[12] K. Terzaghi. Mechanism of landslides. Application of geology to engineering practice, Geol Soc Am pp. 83-123, 1950.

[13] G. Mylonakis, P. Kloukinas, C. Papantonopoulos. An alternative to the mononobe-okabe equations for seismic earth pressures. Soil Dynamics and Earthquake Engineering 27(10):957-969, 2007. 